RESEARCH PAPER RP761

Part of Journal of Research of the National Bureau of Standards, Volume 14, February 1935

\title{
INFLUENCE OF MAGNESIUM SULPHATE ON THE DETE- RIORATION OF VEGETABLE-TANNED LEATHER BY SULPHURIC ACID
}

\author{
By Roy C. Bowker, Everett L. Wallace, and Joseph R. Kanagy
}

\section{ABSTRACT}

The influence of magnesium sulphate on the deterioration of chestnut and quebracho leathers was studied. Samples of both leathers, which contained varying percentages of sulphuric acid, and comparable leathers, which contained similar amounts of sulphuric acid and approximately 5 percent of magnesium sulphate, were examined. The addition of magnesium sulphate caused an increase in the $\mathrm{pH}$ of the leathers. Deterioration was determined by measuring the change in strength after $6,12,18$, and 24 months. Deterioration of the samples aged for 24 months was also determined by measuring the extractable nitrogen. The results by both physical and chemical methods show that, for the same percentage of acid, the leathers containing magnesium sulphate deteriorated less. However, it was found that deterioration was a function of $\mathrm{pH}$ rather than of actual acid content. All leathers below pH 2.8 showed serious deterioration, while the percentage of acid required to cause it varied from .75 to 1.75 percent.

\section{CONTENTS}

II. Materials and methods

III. Results and discussion used.

IV. Summary

\section{INTRODUCTION}

The production of commercial leather requires the use of many materials in addition to skins and tanning agents. One of these materials, sulphuric acid, has long been used for bleaching in connection with the manufacture of vegetable-tanned leather. Enough acid may be introduced during the process to cause serious damage to the leather within a short time. For this reason more attention has been given to limitations on the permissible mineral acidity in leather than to any other criterion in common use for judging quality. The limiting values established in specifications have been dictated largely by experience gained from observations of the behavior of leather in actual service, instead of by accurate information as to the actual quantitative amounts which would bring about deterioration. The latter has been the object of research conducted at the Bureau. ${ }^{1}$

1 R. C. Bowker and E. L. Wallace. The influence of $\mathrm{pH}$ on the deterioration of vegetable-tanned leather by sulphuric acid. BS J. Research 10, 559 (1933) RP548. 
Thirteen lots of leather, specially prepared and treated with varying percentages of sulphuric acid, were studied. The results showed that the percentage of sulphuric acid which would cause serious deterioration in two years varied from 0.3 to 1.8 for the different leathers. Effective acidity, as indicated by $\mathrm{pH}$ measurements, was determined for all of these leathers. It was found that deterioration bore a more definite relation to the $\mathrm{pH}$ of the leather than to the percentage of acid in it. In all cases deterioration started near or at $\mathrm{pH} 3$.

Among the materials considered likely to have an influence on the determination of the acidity of leather and on its deterioration by sulphuric acid are magnesium sulphate, glucose, sulphonated oils, sulphite cellulose extracts, and synthetic tanning materials. This report deals with the influence of magnesium sulphate which is largely used in the finishing of sole and black harness leathers.

\section{MATERIALS AND METHODS USED}

One lot of leather (no.19) was tanned with ordinary quebracho extract and another lot (no. 20) was tanned with powdered chestnut extract. The chemical analyses of these leathers are given in table 1 .

\section{TABLE 1.-Chemical analyses of leathers}

[Results expressed in percentage excepting for degree of tannage and $\mathrm{pH}$ values]

\begin{tabular}{|c|c|c|}
\hline Tanned with & $\begin{array}{l}\text { Lot no. 19, } \\
\text { quebracho }\end{array}$ & $\begin{array}{l}\text { Lot no. } 20 \text {, } \\
\text { chestnut }\end{array}$ \\
\hline $\begin{array}{l}\text { Water solubles. } \\
\text { Hide substance } \\
\text { Grease (P. E. E.) } \\
\text { Moisture. } \\
\text { Insoluble ash. } \\
\text { Combined tannin }{ }^{1}\end{array}$ & $\begin{array}{r}8.10 \\
48.87 \\
3.50 \\
10.97 \\
.10 \\
28.46\end{array}$ & $\begin{array}{r}8.53 \\
50.40 \\
3.25 \\
11.30 \\
.24 \\
26.28\end{array}$ \\
\hline Total & 100.00 & 100.00 \\
\hline $\begin{array}{l}\text { Degree of tannage }{ }^{2} \\
\text { Soluble tans } \\
\text { Soluble nontans } \\
\text { Total ash } \\
\text { Acid (P and } \mathrm{S} \text { ) } \\
\text { pH value } 4\end{array}$ & $\begin{array}{r}58.20 \\
6.59 \\
1.51 \\
.11 \\
.04 \\
5.21\end{array}$ & $\begin{array}{r}52.10 \\
7.11 \\
1.42 \\
.25 \\
3.07 \\
3.90\end{array}$ \\
\hline
\end{tabular}

1 Determined by difference.

2 Ratio of combined tannin to hide substance.

3 Alkalinity.

$4.9 \mathrm{~g}$ of dry leather in $100 \mathrm{ml}$ of distilled water.

Seven hides were used in preparing the leather for each lot. Twentyfour 7 by 16 inch samples were cut from each hide, as shown in figure 1, making a total of 168 for each lot. Each sample was given a code letter designating its location on the hide and a code number designating the hide from which it was cut. Each sample was of sufficient size to permit 12 test specimens to be cut from it as required. This division of a sample is indicated at the lower left in figure 1. The first step was to determine the original tensile strength of the leather. Two specimens, of the shape and size shown in figure 2, were cut from each sample for this purpose.

The 168 samples from each lot were then divided into 8 groups of 21 each. They were treated in a manner to secure 4 groups con- 
taining 0 , and approximately $3 / 4,13 / 4$, and $2 \frac{1}{2}$ percent of sulphuric acid, respectively. The four remaining groups were similarly prepared, but had also approximately 5 percent of magnesium sulphate $\left(\mathrm{MgSO}_{4}\right.$. $7 \mathrm{H}_{2} \mathrm{O}$ ) added. The tensile strength was determined immediately after the treatments by testing two more specimens from each block.

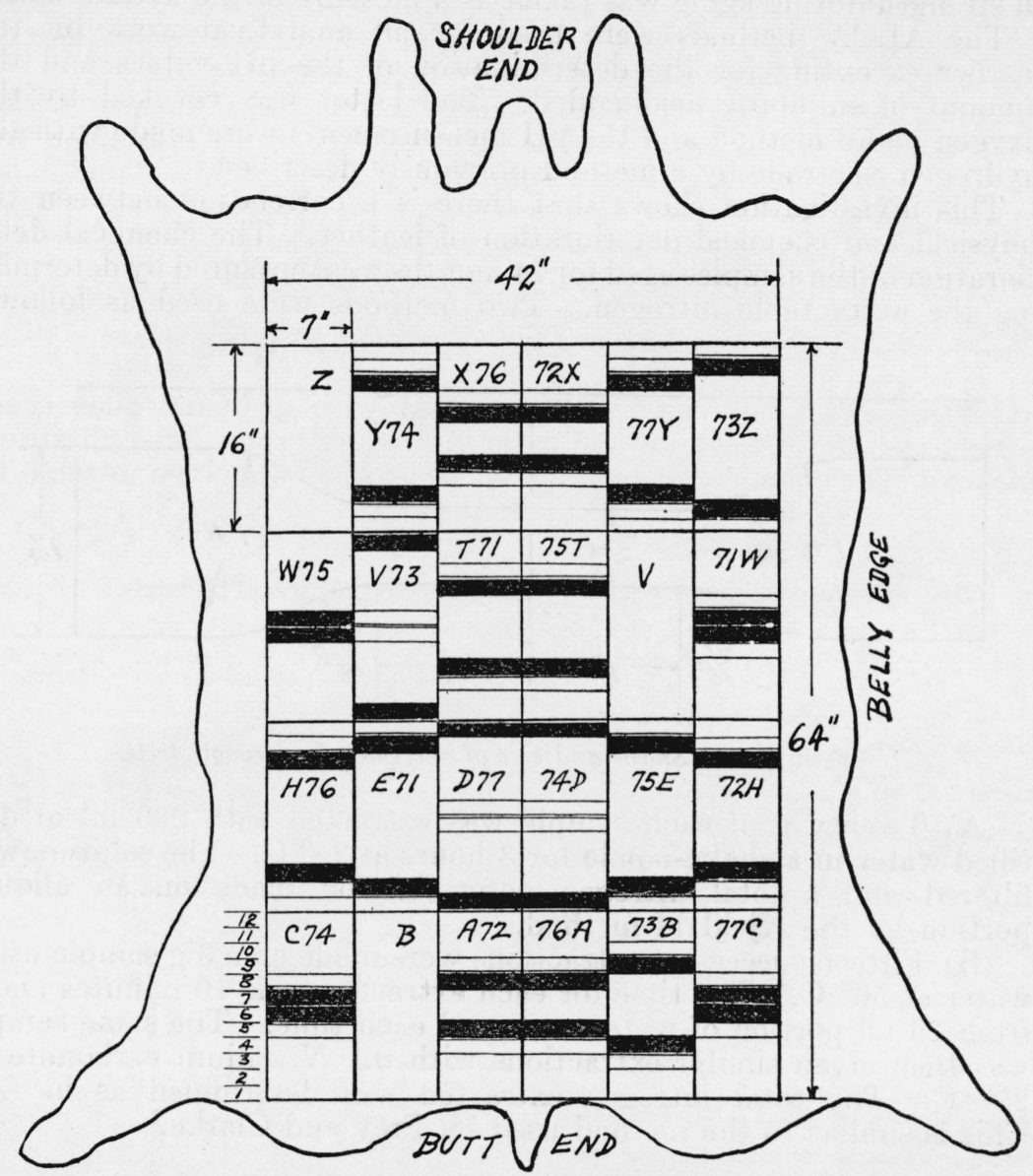

FigURe 1.-Method of sampling.

The leather was then stored at $70^{\circ} \mathrm{F}$, and 65 percent relative humidity and its strength determined after $6,12,18$, and 24 months.

Each group of samples was selected in a manner to make it, as nearly as possible, representative of the lot as a whole. A typical selection of a group of samples is shown in figure 1. It will be noted that samples from each of the hide locations and from each hide were included. The distribution was governed by a statistical study of the strengths of approximately 1,500 samples previously examined in other phases of the subject.

The strength of any group at any period was determined as the average result of 42 tests since two specimens were tested from each sample at each period. Shaded spaces in figure 1 show the 
distribution of the specimens used for determining the original strength of the chestnut leather group which contained 2.4 percent of acid. The open spaces, which in most cases are adjacent to the shaded ones, show the distribution of the specimens used for determining the strength of the group after the 24-month aging period. The change in strength during aging was taken as a measure of the deterioration.

The ALCA methods were used for all analytical work on the leather excepting for the determination of the $\mathrm{pH}$ values and the amount of sulphuric acid added. The latter was checked by the oxygen bomb method and the $\mathrm{pH}$ measurements were made with the hydrogen electrode by a method previously described. ${ }^{2}$

This investigation shows that there is a correlation between the physical and chemical deterioration of leather. The chemical deterioration of the samples aged for 24 months was measured by determining the extractable nitrogen. Two methods were used as follows:

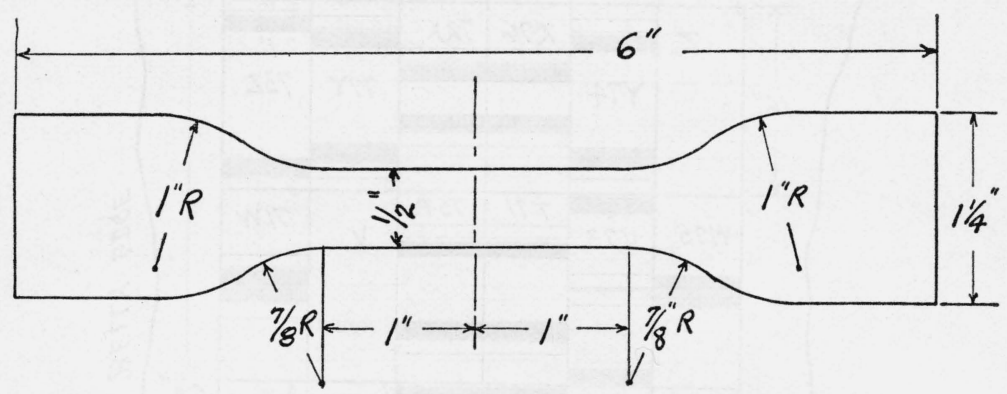

Figure 2.-Shape and size of specimen for strength tests.

(A) Twenty g of each sample was extracted with $200 \mathrm{ml}$ of distilled water in a shake-bottle for 3 hours at $25^{\circ} \mathrm{C}$. The solution was filtered and a total nitrogen determination made on an aliquot portion by the Kjeldahl method.

(B) Fifteen successive extractions were made on a $3 \mathrm{~g}$ sample using water at $50^{\circ} \mathrm{C}$. The time for each extraction was 10 minutes and a fresh $20 \mathrm{ml}$ portion of water was used each time. The same sample was then given similar extractions with $0.1 \mathrm{~N}$ sodium carbonate at $25^{\circ} \mathrm{C}$. The total nitrogen extracted was determined as in (A). This is similar to the method used by Frey and Clarke. ${ }^{3}$

\section{RESULTS AND DISCUSSION}

The percentage of sulphuric acid added, the percentage of magnesium sulphate added, the original $\mathrm{pH}$ values and the $\mathrm{pH}$ values of the samples after aging 24 months are given in table 2 .

\footnotetext{
${ }^{2}$ E. L. Wallace and John Beek, Jr. A comparison of the quinhydrone and hydrogen electrodes in solutions containing tannin. BS J. Research 4, 737 (1930) RP176.

3 The decay of bookbinding leathers. J. Am. Leather Chem. Assn. 26, 461 (1931).
} 
$\mathrm{T}_{\mathrm{ABLE}}$ 2. $-\mathrm{pH}$ values and percentages of acid and magnesium sulphate for the different groups of samples.

[Lot no. 19, Quebracho]

\begin{tabular}{|c|c|c|c|}
\hline \multirow{2}{*}{$\begin{array}{l}\text { Sulphuric } \\
\text { acid }\end{array}$} & \multirow{2}{*}{$\begin{array}{c}\text { Magnesium } \\
\text { sulphate }\end{array}$} & \multicolumn{2}{|c|}{$\mathrm{pH}$} \\
\hline & & Original & 24 months \\
\hline $\begin{array}{r}\text { Percent } \\
0.0 \\
.7 \\
1.6 \\
2.2\end{array}$ & Percent & $\begin{array}{l}4.90 \\
3.26 \\
2.67 \\
2.28\end{array}$ & $\begin{array}{l}4.96 \\
3.32 \\
2.88 \\
2.60\end{array}$ \\
\hline
\end{tabular}

Quebracho With Magnesium Sulphate

\begin{tabular}{|l|l|l|l|}
\hline 0.0 & 4.7 & 4.97 & 4.91 \\
.8 & 4.6 & 3.52 & 3.60 \\
1.5 & 4.9 & 2.81 & 2.98 \\
2.3 & 4.9 & 2.43 & 2.63 \\
\hline
\end{tabular}

Lot no. 20, Chestnut

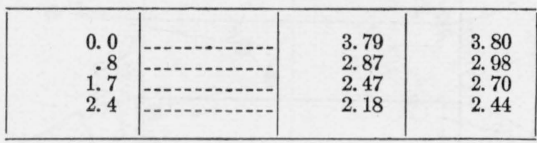

Chestnut With Magnesium Sulphate

\begin{tabular}{|l|l|l|l|}
\hline 0.0 & 5.0 & 3.87 & 3.94 \\
.8 & 5.2 & 3.16 & 3.26 \\
1.7 & 4.9 & 2.64 & 2.80 \\
2.5 & 5.3 & 2.33 & 2.52 \\
\hline
\end{tabular}

The results in table 2 were from a composite of the 21 samples in each group. A consideration of the original $\mathrm{pH}$ values shows that the immediate effect of adding magnesium sulphate is to increase the $\mathrm{pH}$ of the leather. It is of interest to note that the $\mathrm{pH}$ of all groups containing acid increased during aging.

It was previously stated that the strength of any group of samples at any period was the average of the strengths of 42 specimens. Figure 3 shows the strengths of the individual test specimens illustrated in figure 1. The upper values are for the shaded spaces and were used in determining the original strength of the group. The lower values are for the open spaces and were used in determining the strength of the group after treatment with acid and aging for 24 months. The small numbers near the points designate the locations of the specimens on the samples. In this case, the original strength and the strength after 24 months were 3,995 and $2,020 \mathrm{lb} / \mathrm{in} .{ }^{2}$ The loss of strength on aging was approximately 50 percent. Each point in figures 4,5 , and 6 was obtained in this manner. It is of interest to note that the samples from different hides, but from similar hide locations, usually did not vary in strength more than 10 percent.

The results for the deterioration of the leathers are shown in figure 4 for all aging periods as a function of the percentage of sulphuric acid. In graph A the results are shown just as measured. It will 
be noted that there is some change in strength for the control samples which contain no acid. In order to indicate the deterioration caused by the acid, all results have been corrected for the change in strength of the controls and these results are shown in graph B.

The small figures near the points denote the aging period. Those marked with a zero are the results of tests made immediately after

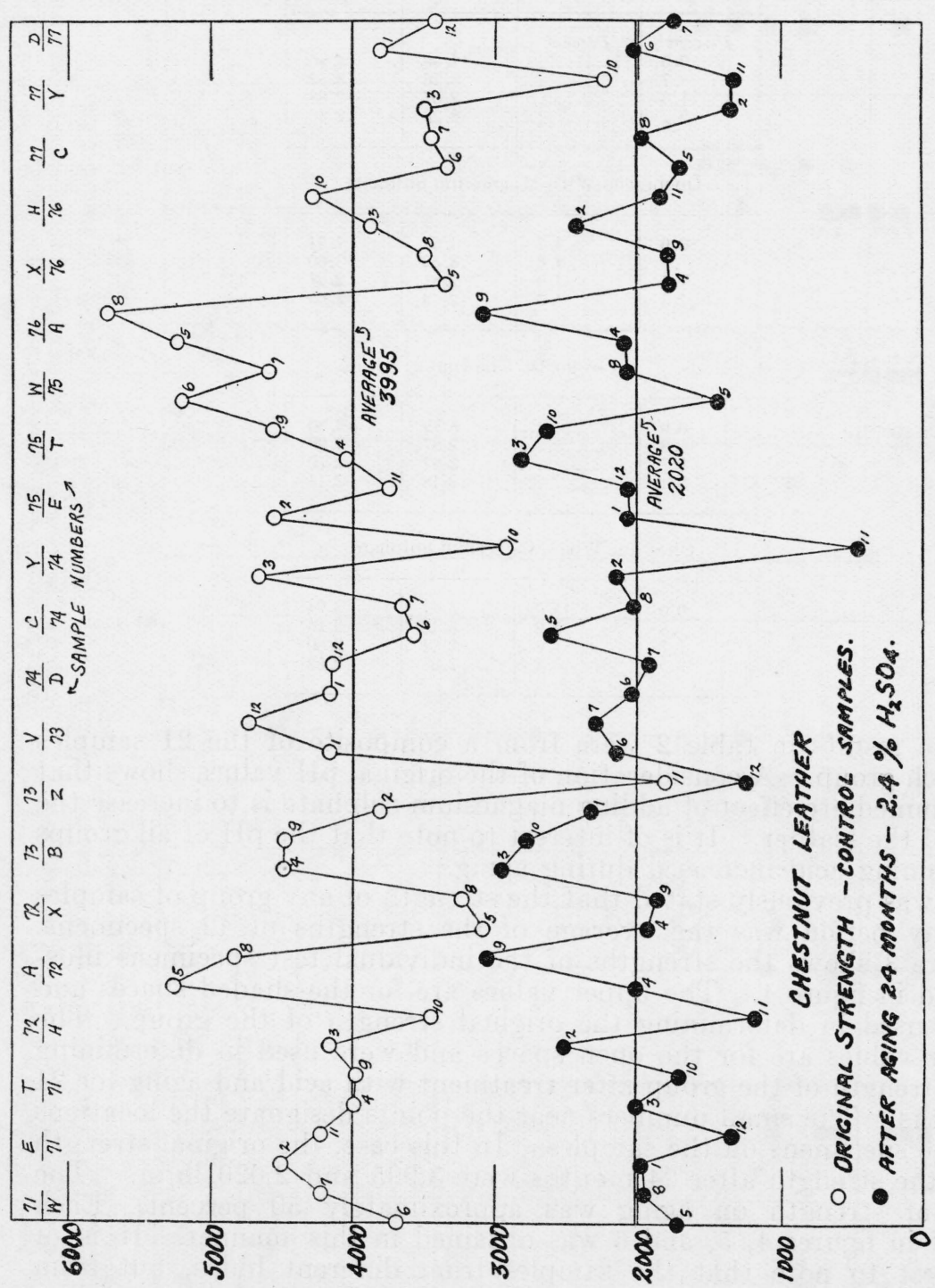

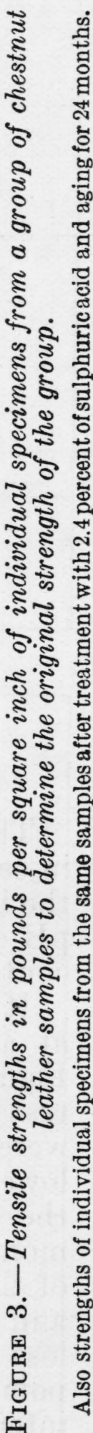

treatment. In most cases the immediate effect of the treatment is to cause a loss in strength which increases with the amount of acid. One exception is the quebracho leather containing magnesium sulphate. This indicated deterioration is considered to be real in view of the fact that the control samples were wetted with water to compensate for any effect due to wetting with acid solutions. It is con- 
sidered in the final results as a part of the total deterioration. It is evident that, for any given acid content, the leather containing
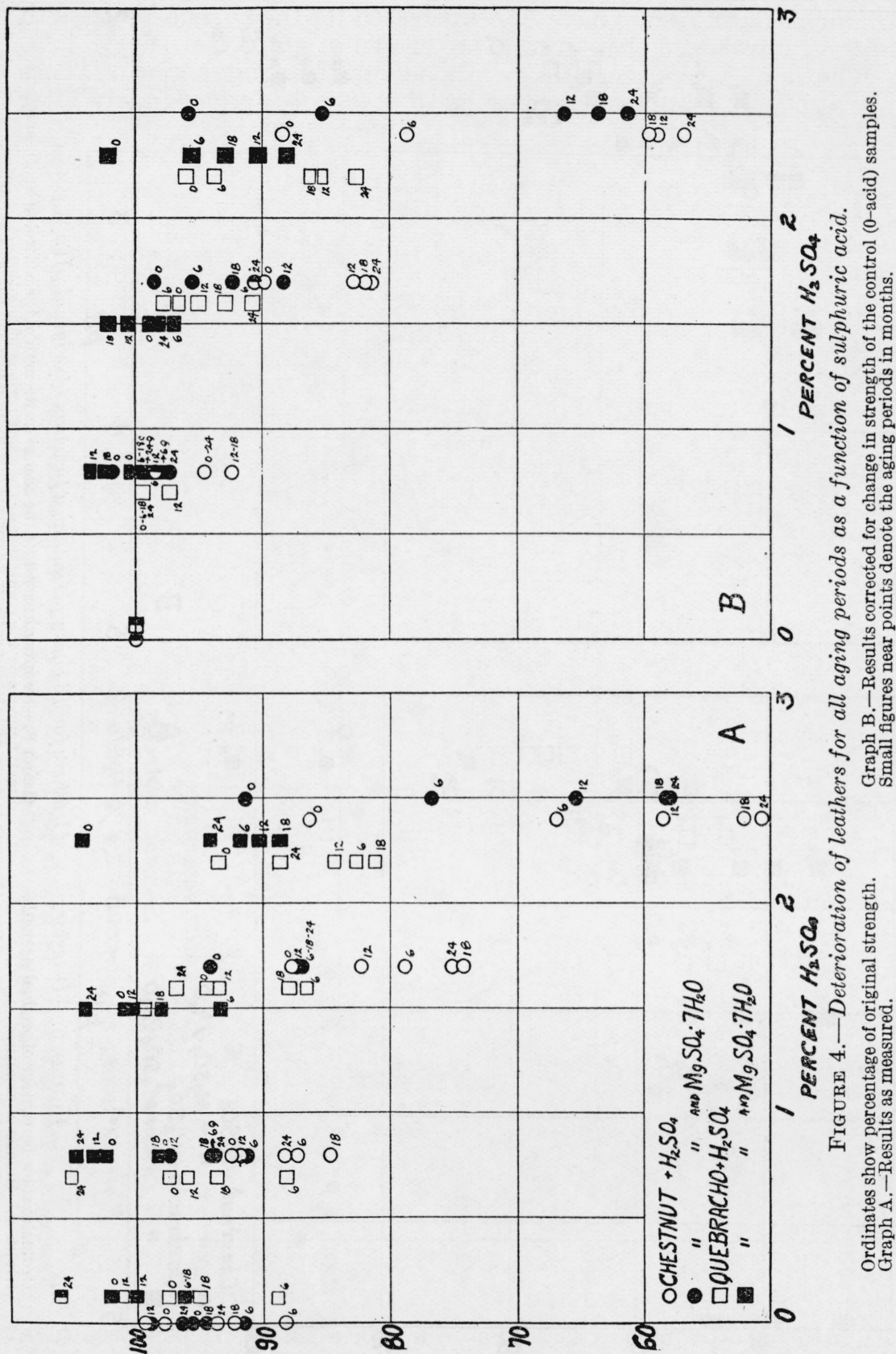

magnesium sulphate did not deteriorate to as great a degree as the leather which did not contain this salt. The results also show little difference in deterioration after 12 and 24 months. The quebracho 
leather, for any given acid content, did not deteriorate as much as the chestnut leather.

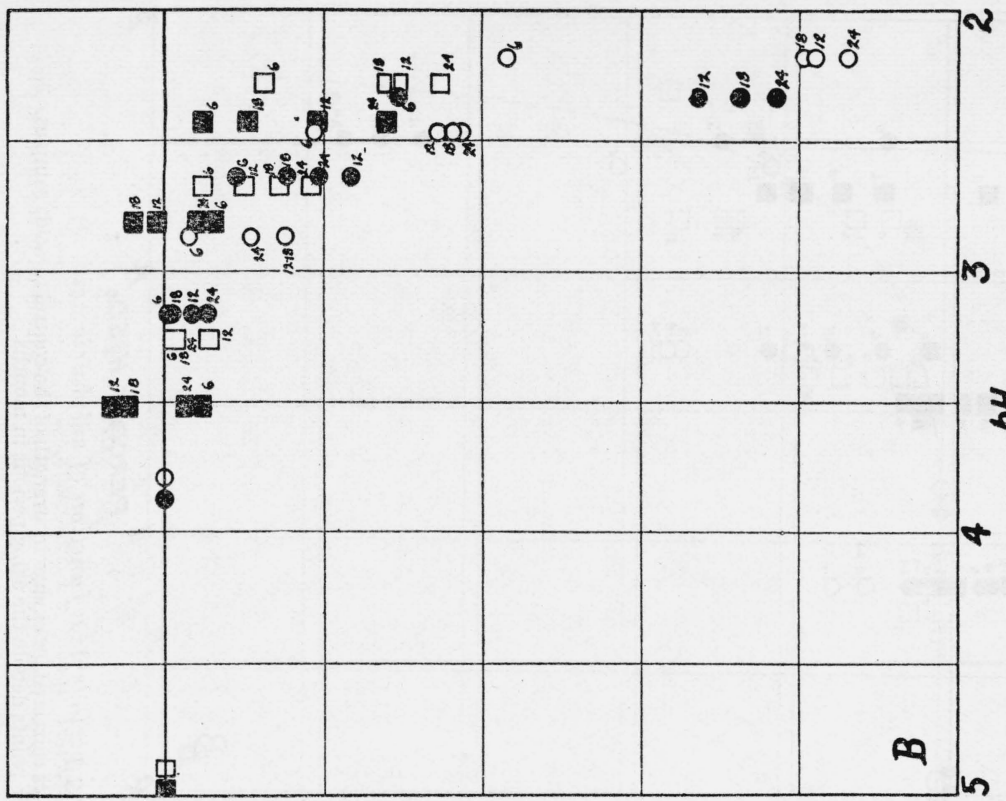

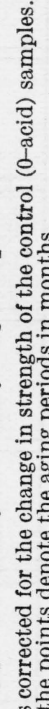

额

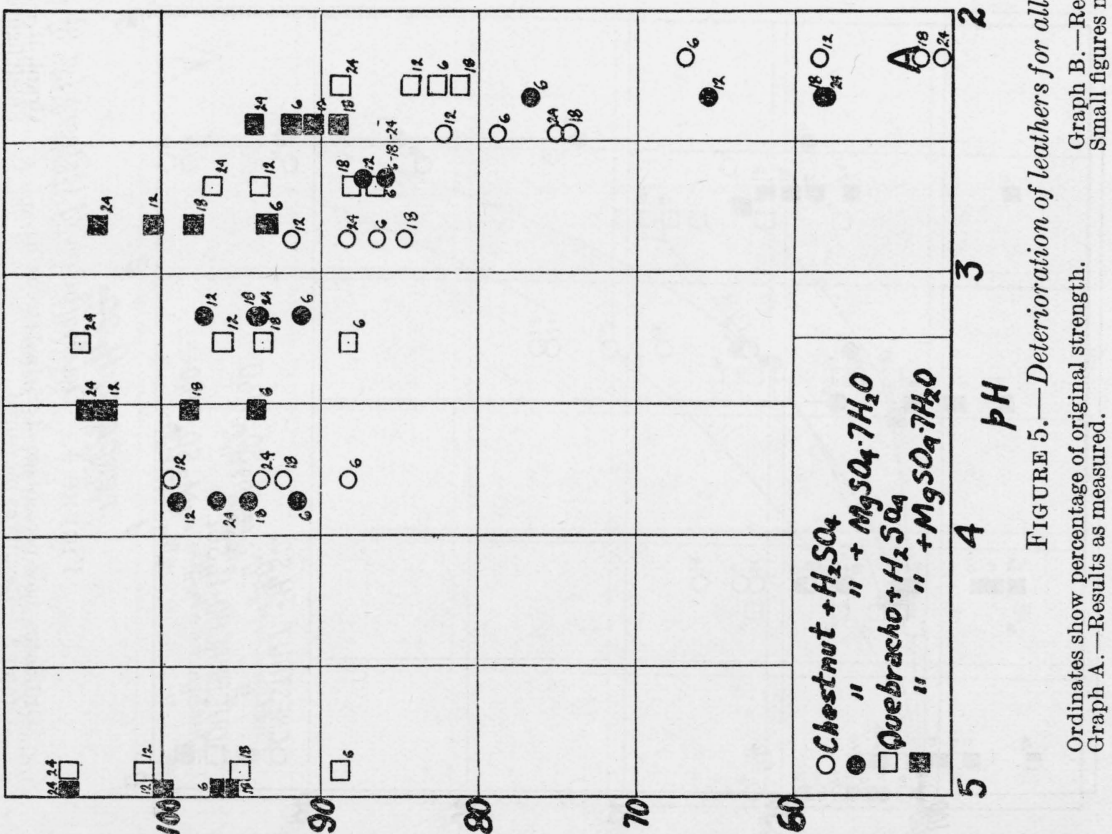

The results for the deterioration of the leathers as a function of the original $\mathrm{pH}$ are given in figure 5 . The results as measured 
are shown in graph A and, as corrected, in graph B. These values show a marked difference when compared with those expressed as a

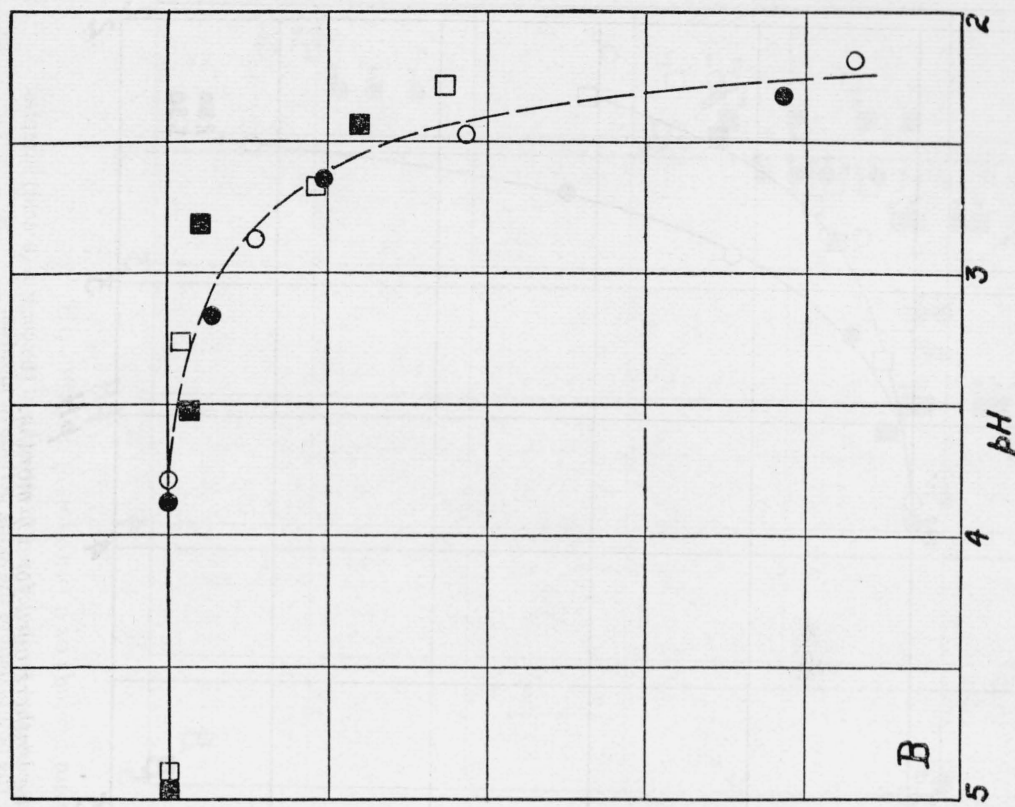

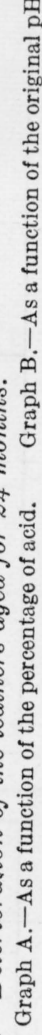
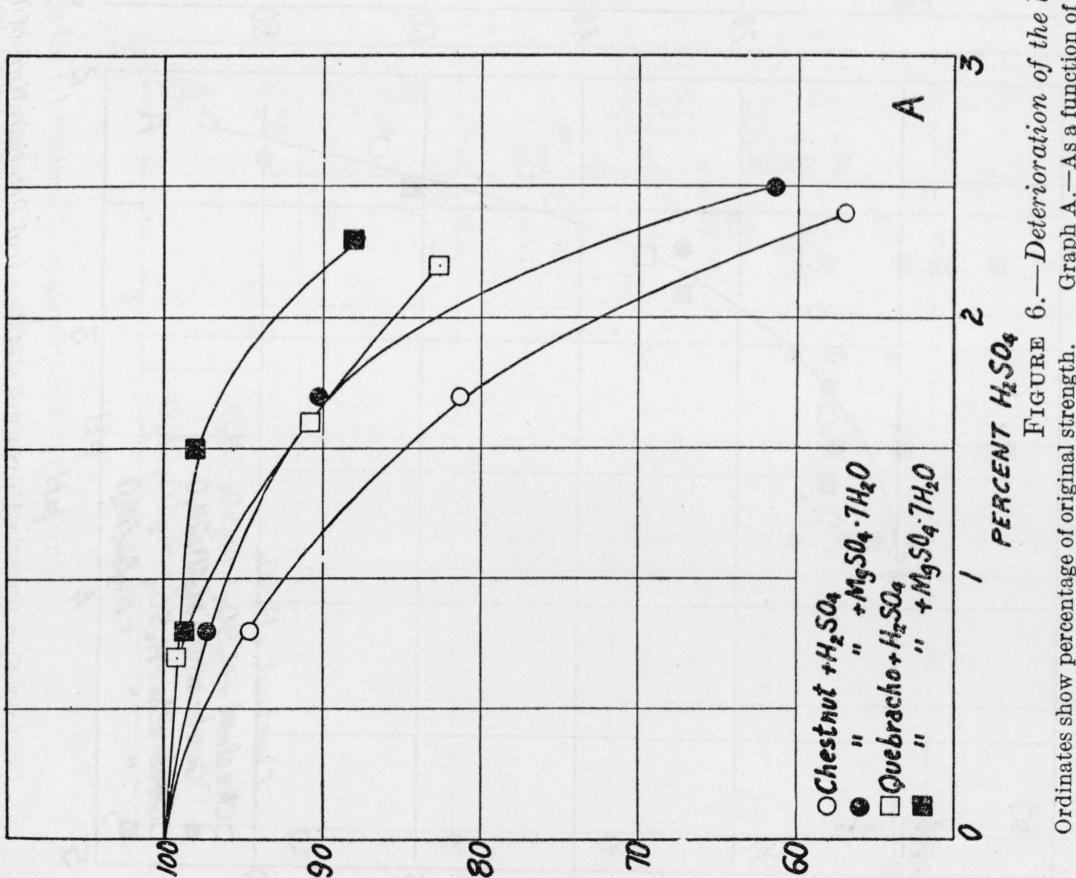

function of the percentage of acid. In the latter case, figure 4, the samples containing magnesium sulphate very definitely showed less 
deterioration than those containing none of this salt. There is no such definite trend shown when the results are expressed as a function
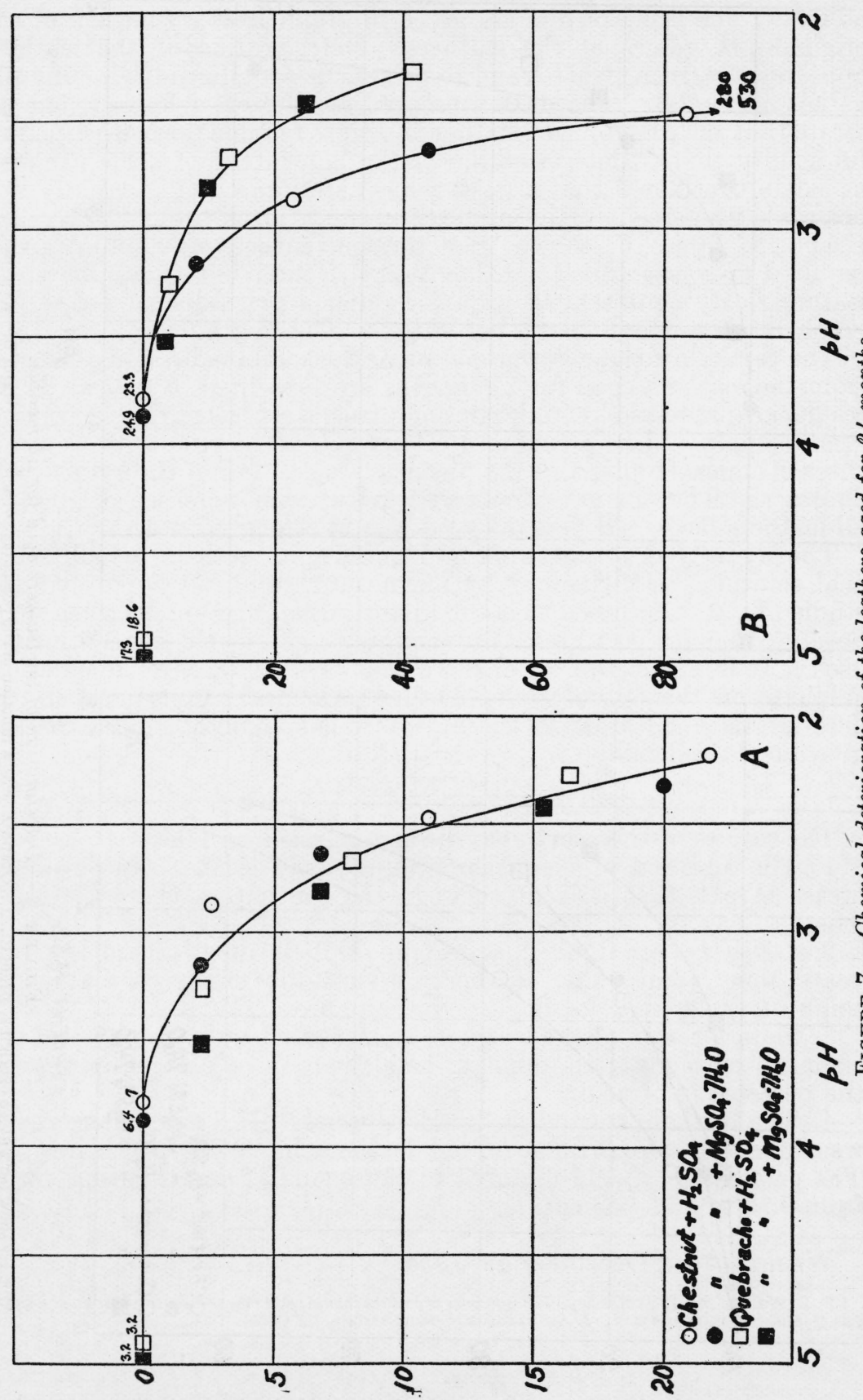

of the original $\mathrm{pH}$ values of the leathers. This is clearly illustrated by the results, figure 6 , for the samples aged for 24 months. Graph 
A shows the deterioration of the leathers as a function of the percentage of acid. The leathers containing magnesium sulphate have clearly lost less strength than the companion leathers containing no salt. The same results are given in graph B as a function of the original $\mathrm{pH}$ values of the leathers. Deterioration of the leathers appears to start near $\mathrm{pH} 3$ and to be serious for all groups having $\mathrm{pH}$ values below 2.8. The data presented in figure 6 definitely demonstrate that the $\mathrm{pH}$ value of leather is a more reliable measure of harmful acidity than a determination of the percentage of acid. It may be safely considered that a leather has deteriorated only slightly if it possesses 95 percent of its original strength after aging for 2 years. Graph A, figure 6, shows that the percentage of sulphuric acid required to meet this condition varies from .75 to 1.75 for these leathers. By contrast, all groups having a $\mathrm{pH}$ value of below 2.8, graph B, show more than 5 percent loss in strength.

The results for the determinations of the soluble nitrogen extracted from the leathers aged for 24 months are presented in figure 7. All results are expressed in milligrams of nitrogen extracted from a twentygram sample and as a function of the $\mathrm{pH}$. The similarity between these chemical results and the physical results, graph B, figure 6 , will be noted. The amount of nitrogen extractable increases sharply for all leathers below $\mathrm{pH} 3$ as does the loss in strength on aging.

The hydrolysis of chestnut and quebracho leathers in sulphuricacid solutions as influenced by magnesium sulphate was previously studied. ${ }^{4}$ It was shown that the hydrolysis was retarded, when magnesium sulphate was present, over the range of acid concentrations used. It is of interest to observe that the influence of magnesium sulphate on the hydrolysis of leather in acid solutions and on the deterioration of leather in the dry state is strikingly similar for any given acid condition.

\section{SUMMARY}

The results of this work may be summarized as follows:

1. The addition of magnesium sulphate to leather caused an increase in $\mathrm{pH}$, that is, a decrease in the concentration of hydrogen ions.

2. Leathers containing magnesium sulphate deteriorated less in 2 years than comparable leathers having the same percentage of sulphuric acid and no magnesium sulphate.

3. Deterioration of the leathers, as measured by both physical and chemical methods, was found to be a function of $\mathrm{pH}$ rather than of the percentage of acid.

4. The leathers started to deteriorate near $\mathrm{pH} 3$ and deterioration was of major proportions for all leathers having a pH below 2.8. The percentage of acid required to cause similar deterioration varied from 0.75 to 1.75 percent.

Washington, December 19, 1934.

1 E. L. Wallace and J. R. Kanagy. The influence of sodium chloride and magnesium sulphate on the hydrolysis of leather by sulphuric acid. J. Am. Leather Chem. Assn. 4, 186 (1933). 